\title{
NEW MICRO-MILL CONCEPTS WITH BELT CASTING TECHNOLOGY (BCT®)*
}

\author{
Ernst Lindemann ${ }^{1}$ \\ Jochen Wans ${ }^{2}$ \\ Christian Geerkens ${ }^{3}$ \\ Dirk Austermann ${ }^{4}$ \\ Hermann Cremers ${ }^{5}$
}

\begin{abstract}
Steel suppliers are required to deliver sheets with particular qualities and with lightweight-potential to the automotive industry. New types of steel call for new production processes. SMS group has developed a new micro-mill-concept, the core of which is the belt caster. This was first built on an industrial scale and has been put into operation and developed together with Salzgitter Flachstahl $\mathrm{GmbH}$. The robustness in industrial-scale operation could be verified. The full use of the belt casting technology, mainly related to energy efficiency and $\mathrm{CO}_{2}$ reduction, is realized with the micro-mill-concept. This is an in-line-process, casting and rolling in one line. Keywords: Micro-mill; Near-net-shape; Belt casting technology; High-alloy steel grades.
\end{abstract}

1 Dipl.-Ing. (FH), Senior Application Engineer, Technical Sales, SMS Siemag do Brasil, Belo Horizonte, Minas Gerais, Brazil.

2 Dr.-Ing., General Manager Technical Sales Technical Sales Special Technologies / New Developments Department, SMS group, Düsseldorf, Germany.

3 Dipl.-Ing., Executive Vice President Metallurgical Plants and Environmental Technology Division, SMS group, Düsseldorf, Germany.

4 Dipl.-Ing., Senior Project Manager, Technical Sales Technical Sales Special Technologies / New Developments Department, SMS group, Düsseldorf, Germany.

5 Dipl.-Ing., Manager Technology and Commissioning Department, SMS group, Düsseldorf, Germany. 


\section{$1 \mathrm{BCT}^{\circledR}$ - THE TECHNOLOGICAL LEAP}

Unlike many other materials, steel is subject to ever increasing requirements. Hightech components made of modern steels already offer a variety of applications. In the future the manufacture of innovative products requires the availability of steel grades with significantly improved properties.

Steelmakers are therefore faced with the challenge of developing new steel alloys that satisfy the specific requirements. However, the production, use and recycling of steel today must also comply with environmental standards.

Especially high and ultra-high alloy steel concepts for use in the manufacture of lightweight automobiles, offshore applications or in the chemical industry are needed. Where these alloys are used, they combine optimal mechanical properties and thus present steelmakers and their existing plant and equipment with new challenges [1].

Plant and equipment builders must develop suitable plant and processes for their customers. The focus here is on the further development of existing processes which offer customers a financial benefit. One example of this is SMS group's CSP ${ }^{\circledR}$ technology which has been existing since 1989. Another main area is the development of novel plant concepts.

The newly developed plant concept based on Belt Casting Technology $\left(\mathrm{BCT}^{\circledR}\right)$ is now realized by SMS group for the first time on an industrial scale (fig. 1).

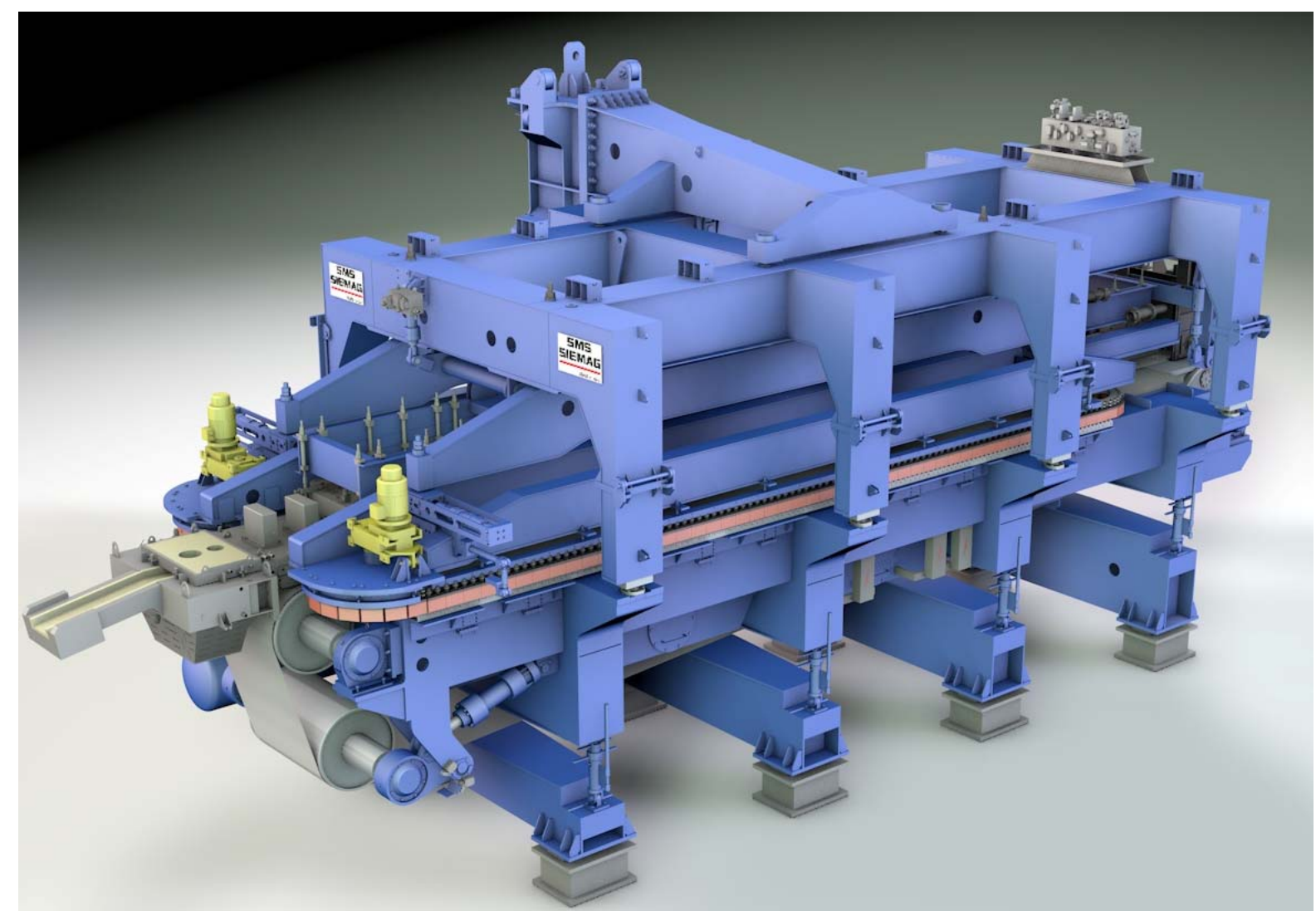

Figure 1: $\mathrm{BCT}^{\circledR}$ caster

In cooperation project with Salzgitter Flachstahl $\mathrm{GmbH}$ this plant is used to implement the near-net-shape casting of $\mathrm{HSD}^{\circledR}$ steel grades. Main technological expertise has been developed together with Clausthal University. The mechanical engineering of SMS group presents the basis for the commercial launch of this 
forward-looking casting technology. SMS group thus will extend its portfolio of custom-made and energy-efficient casting and rolling installations.

The revolutionary Belt Casting Technology is another technology leap on the way to near-net-shape casting. $\mathrm{BCT}^{\circledR}$ casters will allow different production rates and a large variety of product sizes, depending on the desired plant concept. The product line for $\mathrm{BCT}^{\circledR}$ casters will mainly comprise alloys that so far could not be continuously cast, as well as crack-critical conventional steel grades.

With the present paper the cooperation partner wish to highlight the advantages of the technology and the commissioning progress of the first industrial-scale $\mathrm{BCT}^{\circledR}$ caster. (HSD® is a registered brand of Salzgitter Flachstahl $\mathrm{GmbH}$.)

\section{THE FIRST INDUSTRIAL-SCALE BCT ${ }^{\circledR}$ CASTER}

The near-net-shape horizontal belt casting of steel opens up new technological possibilities.

Many of the steel grades which presently entail yield losses in conventional plants are expected to be profitably produced in $\mathrm{BCT}^{\circledR}$ installations. Steels with extraordinary properties can now for the first time be produced on an industrial scale: $\mathrm{HSD}^{\circledR}$ steel [2] with its high contents of manganese, silicon and aluminum: lightweight, high strength and at the same time easily deformable.

All is made possible by casting metal onto the moving mold without the addition of casting flux, as well as stress-free horizontal solidification of the as-cast strip.

The rapid solidification in an inert atmosphere opens up a wide range of potential charge materials [3]. The caster may be combined both with BOF and electric arc furnace melt shops. $\mathrm{BCT}^{\circledR}$ installations may be specifically tailored to the needs of SMS group's customers. Medium-wide strip can be produced just as well as hot wide strip.

Customers with small production capacities will be served by the appropriate installation, as well steel producers with medium-to-high annual tonnages.

The caster will be designed for the necessary metallurgical length and casting speed. Compact $\mathrm{BCT}^{\circledR}$ casting-rolling installations produce $15 \mathrm{~mm}$ as-cast strip - a near-netshape thickness that allows both a sufficient deformation degree to attain optimal mechanical properties and saves deformation energy, space and eventually cost.

In May 2010, Salzgitter Flachstahl awarded SMS group a contract for the construction of the world's first horizontal, industrial-scale BCT $^{\circledR}$ caster.

Utilizing existing infrastructure, a financial first-plant concept could be drawn up in cooperation with Salzgitter, whose focus is on testing of the casting technology. SMS group's wealth of experience in the planning, construction and trial operation of the pilot plants set up at the MEFOS Research Institute in Sweden as well as at the technological competence of Technical University of Clausthal are essential factors that contributed to the development and design of the new machine. The laboratory strip caster at the Institute of Metallurgy of the Technical University of Clausthal was used to successfully cast the novel HSD ${ }^{\circledR}$ steel grades.

The new $\mathrm{BCT}^{\circledR}$ caster is installed at Peiner Träger $\mathrm{GmbH}$ (Salzgitter Group) steelworks (Fig. 2). The HSD ${ }^{\circledR}$ steel grades on which the focus is here are made using the SMS group supplied and commissioned units comprising electric arc furnace with ARCCESS ${ }^{\circledR}$ technology, twin-type ladle furnace and vacuum degasser. The $\mathrm{BCT}^{\circledR}$ caster produces $15 \mathrm{~mm}$ thick and $1,000 \mathrm{~mm}$ wide material. Essential parts of the plant are already rated for a width of $1,600 \mathrm{~mm}$ to allow the future extension of the product line. 


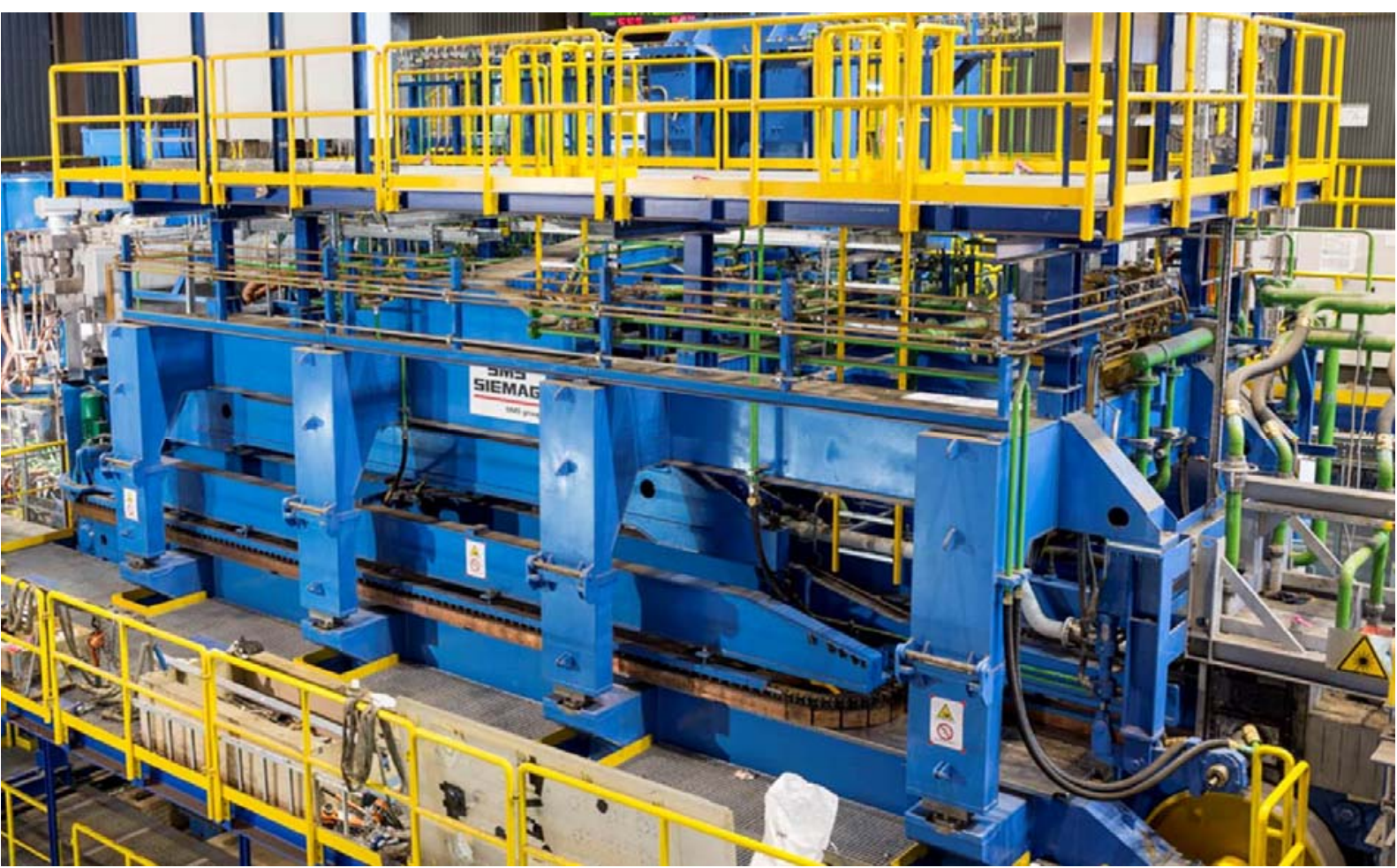

Figure 2: Set-up of BCT® caster in Peine.

At the Salzgitter works, an existing four-high mill stand was upgraded to allow the further processing of the as-cast strip produced in Peine.

SMS group supplied the Basic and Detail Engineering, all mechanical plant components including the complete X-Pact ${ }^{\circledR}$ electrical and automation package and erected the equipment for the $\mathrm{BCT}^{\circledR}$ caster and the modernization of the mill stand.

In December 2012, the cooperation partners Salzgitter Flachstahl and SMS group did jointly commission the facilities in order to implement the benefits of this technology on an industrial scale.

Footprint of the machine is approx. $11 \mathrm{~m} * 4 \mathrm{~m}, 6 \mathrm{~m}$ tall. Machine length is owing to the solidification range of special steel grades.

Protected from reoxidation, the liquid steel is poured from a conventional ladle into a covered tundish and from there, via the submerged entry nozzle, into the preheated feeding system (Fig. 3). From this system the steel flows onto the moving horizontal mold which consists of the conveyor belt and the internally cooled side dams.

The underside of the conveyor belt is intensively cooled by water. No oscillating mold is therefore needed for initial solidification and no addition of casting flux is required. Above the conveyor belt an inert gas atmosphere protects the solidifying steel. At the rear end of the caster, a defined gas mixture directly influences the solidification structure. 


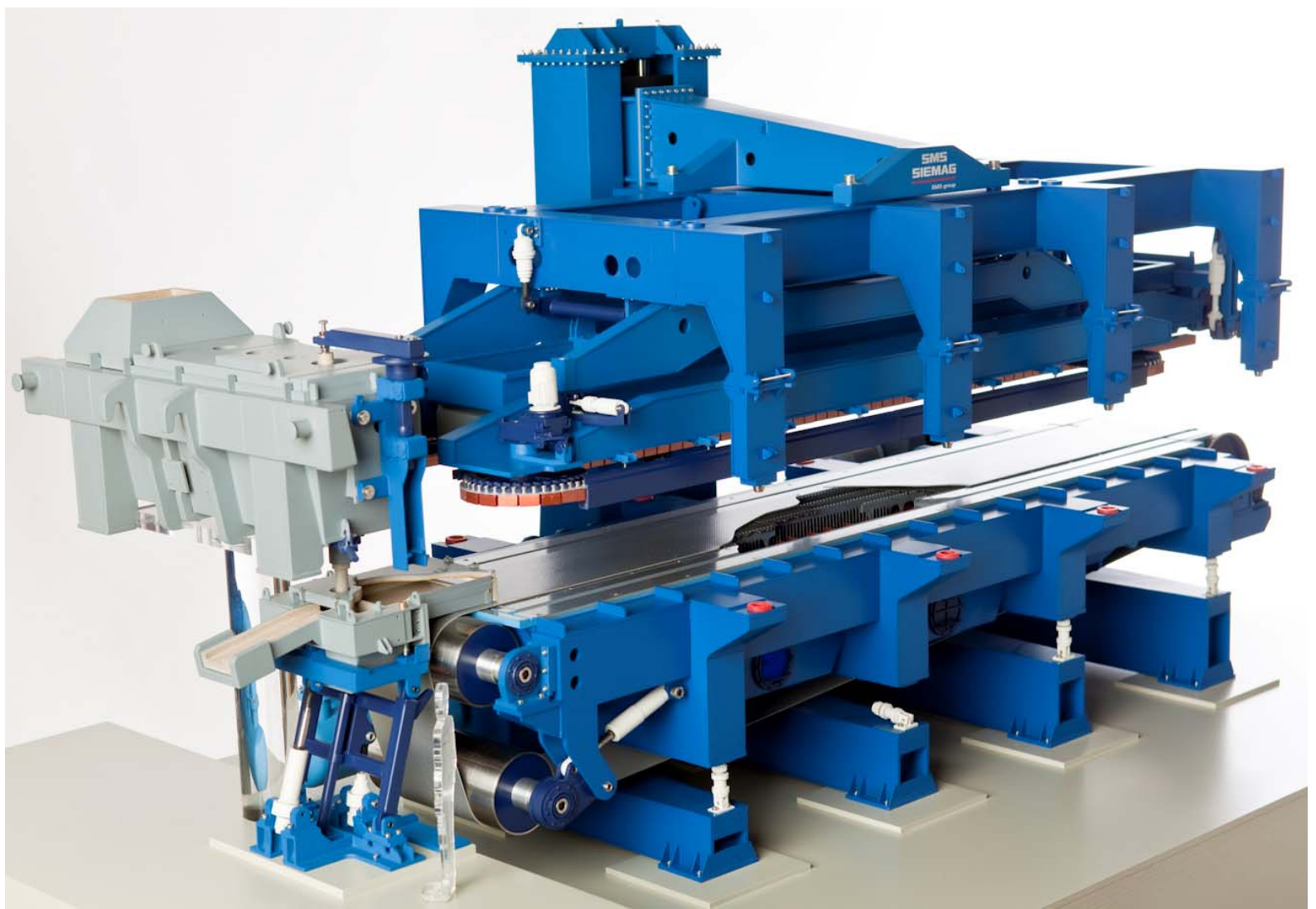

Figure 3: Tundish, feeding system and $\mathrm{BCT} \circledast$ caster with lifted top frame

Electro-magnetic units to influence the steel flow as well as cooled hoods are arranged above the conveyor belt. A transverse stirrer supports the smooth and uniform distribution of the liquid steel up to the side dams. A longitudinal stirrer synchronizes the movement of the conveyor belt with the liquid steel flow. This stirring technology is the result of a joint development. SMS Elotherm $\mathrm{GmbH}$ delivered both units.

The as-cast strip leaves the conveyor belt horizontally (Fig. 4). It is guided by a top roller and three pairs of ironing rollers that can influence the flatness of the strip. Downstream these rollers both the strip thickness and profile are measured. The ascast strip then enters an enclosed roller table in which the complete inertization of the process is ensured up to the end of the table.

The roller table is followed by a combination of two pinch-roll stands and a looper arranged in between. In addition to the further transport of the as-cast strip, it makes sure that influences which downstream units have on the as-cast strip are decoupled. The second pinch roll unit feeds the strip to a moving hydraulic shear. For cutting, the shear is accelerated to the as-cast strip speed, cutting it to the desired sheet length. 


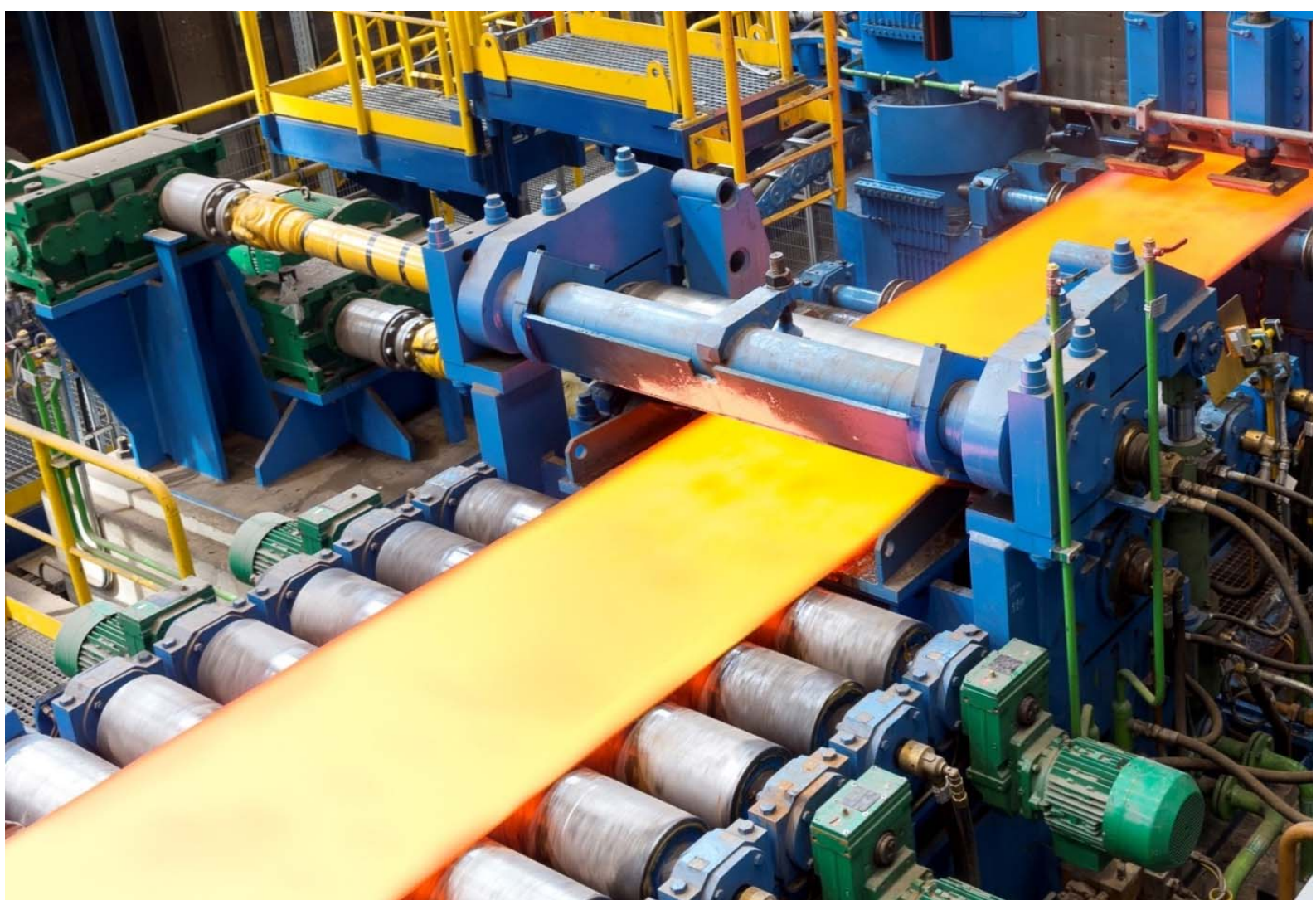

Figure 4: As-cast strip at pinch-roll and shear

A roller table accelerates the sheets which here have a maximum length of $9 \mathrm{~m}$; towards the end of the roller table the sheets are decelerated again. Cross-pushers place the sheets on a hydraulically operated lifting table. The sheets stacked on pallets are loaded onto wagons and taken to the rolling mill in Salzgitter.

\section{NEW MICRO-MILL CONCEPTS WITH BELT CASTING TECHNOLOGY (BCT $\left.{ }^{\circledR}\right)$}

In December 2012, Salzgitter Flachstahl and SMS group started the commissioning of the BCT plant. Since then a continuous improvement of the equipment and process, driven by many trials with varied casting parameters, lead to highly promising results. The process reproducibility and the plant availability match the requirements.

Satisfactory answers were obtained on process-related basic questions concerning wear and service life of different machine components of the caster, such as the casting nozzle, the conveyor belt and the moving side dams. One of the main aims of the first industrial scale BCT® plant in Peine was to verify the capability of the Belt Casting Technology under industrial conditions. Under the circumstances the casting and rolling was realized cost efficient at two separate locations (Fig.5).

Due to the successful results SMS group started investigations in the next step. SMS has developed a new micro-mill concept, the core of which is the belt caster. The full use of the belt casting technology, mainly related to energy efficiency and $\mathrm{CO} 2$ reduction, is realized with the micro-mill-concept. This is an in-line-process, casting and rolling in one line (Fig.5 and Fig.6) 


\section{Current Pilot-Layout: Casting - Cooling - Transportation - Reheating - Rolling}

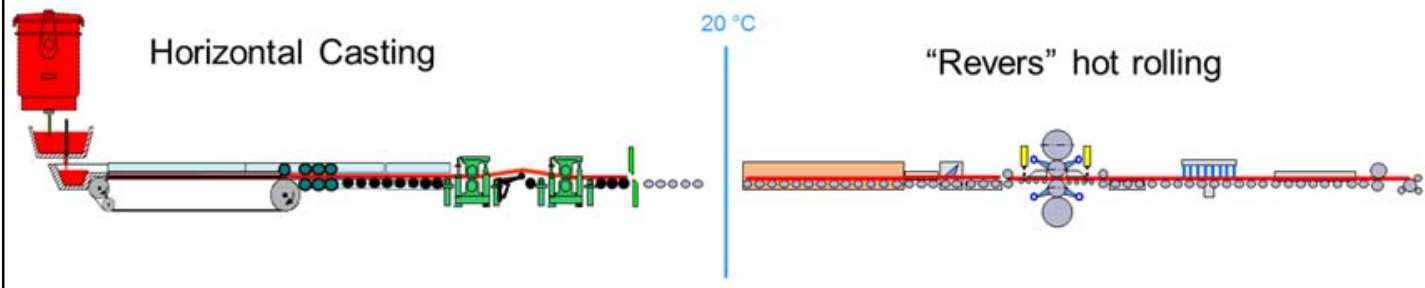

\section{Inline-Layout: Casting - Rolling}

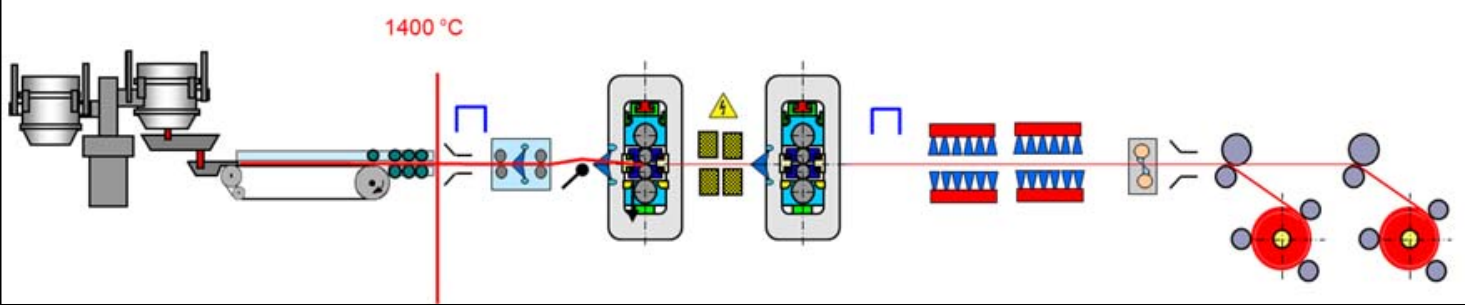

Figure 5: Current pilot layout as installed in Peine and Salzgitter and the new micro-mill concept: BCT casting and rolling inline.

The shown inline-layout was developed in the context of a project for an annual production of 300.000-500.000 t/a, a hot strip thickness of 3-4 mm and a width of $1300 \mathrm{~mm}$. This application provides an endless concept with the following advantages:

- No roller hearth furnace necessary, therefore less energy consumption and eco-friendly $\rightarrow$ low OPEX

- Low entrance thickness $(14-20 \mathrm{~mm}$ ) leads to reduced number of mill stands $\rightarrow$ low CAPEX

- Simple caster compared to conventional caster with reduced maintenance $\rightarrow$ low CAPEX and OPEX

- Indirect water cooling only by closed loop, no open spray cooling, no make-up water $\rightarrow$ low OPEX

- Compact plant design with low space requirement (approx. $160 \mathrm{~m}$ ) $\rightarrow$ low CAPEX

Due to the unique casting conditions coming along with $\mathrm{BCT}^{\circledR}$ like no casting powder and oscillation necessary, horizontal casting on moving mold with quick solidification, inert atmosphere and no stress induced by bending/unbending combined with a low casting thickness between $14-20 \mathrm{~mm}$, which reduces the rolling work, the technique is fit for standard steel grades and particular for special steel grades like Ultra High Strength Steels (UHSS), High Aluminum alloyed Steels and High Manganese alloyed Steels.

It is a tool which enlarges the range of producible steel grades of today and of your future steel grade developments. 


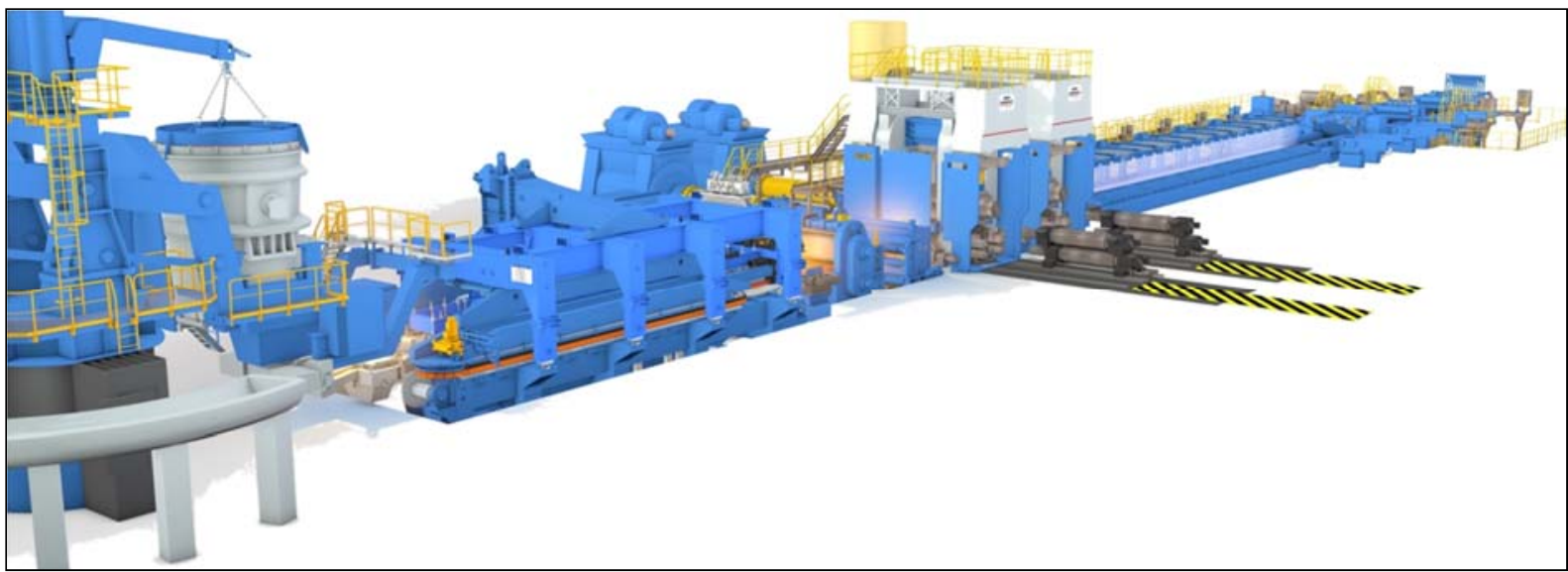

Figure 6: Three-dimensional design of Micro-mill concept: $\mathrm{BCT}^{\circledR}$ casting and rolling inline.

\section{CONCLUSIONS}

The Belt Casting Technology $\left(\mathrm{BCT}^{\circledR}\right)$ is realized by the plant builder SMS group for the first time on an industrial scale. In cooperation project with Salzgitter Flachstahl $\mathrm{GmbH}$ this plant is used to implement the near-net-shape casting and offline rolling of $\mathrm{HSD} \otimes$ steel grades.

Since the commissioning the $B C T^{\circledR}$ caster produces mainly $15 \mathrm{~mm}$ thick and 1,000 $\mathrm{mm}$ wide as-cast strip. The product mix leads from medium carbon grades up to high Manganese steel grades with Aluminum and Silicon. The results achieved up to today are highly promising. Therefore SMS group started investigations in inline processes.

The full use of the belt casting technology, mainly related to energy efficiency and $\mathrm{CO}^{2}$ reduction, is realized with the micro-mill-concept, which is an in-line-process, casting and rolling in one line. Depending on customers request regarding steel grades and strip dimensions the concept will be designed and adopted individually.

The Belt Casting Technology enables the production of new steel alloys, with horizontal strip casting offering an opportunity to produce steel grades which in conventional installations can be cast to a limited extent only. BCT ${ }^{\circledR}$ is characterized by stress-free solidification, with no casting flux required for this process. Together with Clausthal University the basis of the process technology has been developed. The full benefits of belt casting technology regarding OPEX and CAPEX can be achieved by inline concepts.

$\mathrm{BCT}^{\circledR}$ installations are flexible when it comes to their integration in new or existing BOF or electric arc furnace melt shops.

\section{REFERENCES}

1 Gigacher, G., Bernhard, C., Kriegner, W. Eigenschaften hochmanganhaltiger Stähle unter stranggießähnlichen Bedingungen, BHM, 149 (2004) No. 3, pp. 112-117.

2 Kämper, S.: Forschungsinnovation für den Kunden, Stahl und Eisen 129 (2009) Nr. 6

3 Spitzer, K.-H., Rüppel, F., Viscorova, R., Scholz, R., Kroos, J., Flaxa, V. Direct Strip Casting - an Option for the Production on New Steel Grades, steel research 74 (2003) No. $11 / 12$, pp. $724-731$ 